\title{
LA REGULACIÓN ARGENTINA DEL PROCESO CONSULTIVO ANTE EL TPR: UTILIDAD DE LA MISMA
}

\section{A REGULAC̄ÃO ARGENTINA DO PROCESSO DE CONSULTA AO TPR: SUA UTILIDADE}

Martin Canepa ${ }^{\star}$

Resumen: Los sistemas de integración que han ido surgiendo a través de la historia han creado distintas vías para la resolución de conflictos propios del derecho comunitario la interpretación de sus normas. Los procedimientos varían de acuerdo al sistema que estemos analizando y en relación al tema planteado, pero lo cierto es que los sistemas latinoamericanos como el Mercosur se han nutrido de la experiencia europea. En este caso nuestro trabajo se concentrará en el análisis del proceso consultivo ante el Tribunal Permanente de Revisión en relación a la regulación hecha por la Republica Argentina. A su vez es interesante destacar la jurisprudencia que resultó pionera en la materia, y vislumbrar cuales fueron las consecuencias jurídicas de la misma. El proceso de solicitud de opinión consultiva en el Mercosur entraña una gran importancia por el hecho de que se trata de un procedimiento que pese a sus limitaciones, propias de un sistema intergubernamental, constituye el camino para lograr la uniformidad y transparencia en la aplicación e interpretación del derecho Mercosureño. Es por ello que el Tribunal Permanente de Revisión haciendo uso de este procedimiento, cuando le sea solicitado, podrá darle vida al sistema y hacer que éste avance cada vez más y se consolide en el tiempo.

Resumo: Os sistemas de integração que surgiram ao longo da história criaram várias formas de resolver conflitos típicos do direito comunitário e de interpretação das suas regras. Os procedimentos variam de acordo com o sistema que estamos analisando e com a questão suscitada, mas a verdade é que os sistemas como o Mercosul na América Latina não têm sido elaborados a partir da experiência européia. Neste caso, nosso trabalho terá como foco a análise do processo de consulta ao Tribunal Permanente

\footnotetext{
* Abogado (Orientación: Derecho Internacional Público). Auxiliar docente - Derecho de la Integración (Cátedra Calogero Pizzolo). Miembro del equipo de investigación Decyt (UBA) 2012-2014 "Sistema de Solución de Controversias en el Mercosur: ¿camino a un Tribunal de Justicia? Miembro del equipo seleccionado por la facultad de derecho (UBA) para la participación en la " 60 Edición del Concours d'Arbitrage International de Paris" organizado por la Ecole de Droit de Sciences Po (30 y 31 de mayo 2011, Paris, Francia).
} 
de Revisão sob a perspectiva do regulamento estabelecido pela República Argentina. Também se mostra interessante observar um de seus casos pioneiros e vislumbrar quais foram as consequências legais do mesmo. $O$ procedimento solicitação de opiniões consultivas no Mercosul tem grande importância, já que consiste, apesar de suas limitações, em procedimento típico de um sistema intergovernamental e em caminho para alcançar a uniformidade e transparência na aplicação e interpretação do direito do Mercosul. É por isso que o Tribunal Permanente de Revisão, ao usar este procedimento, quando seja solicitado, poderá dar vida ao sistema e contribuir a sua consolidação e desenvolvimento.

Palabras clave: Integración, Mercosur, Proceso consultivo, Tribunal Permanente de Revisión

Palavras-chave: Integração, Mercosul, Processo de consulta, Tribunal Permanente de Revisão

\section{INTRODUCCIÓN}

El proceso consultivo ante el TPR resulta un elemento de suma importancia en relación al desarrollo y evolución del derecho de la integración cuyo objetivo debe ser constituirse en un derecho supranacional. Si bien es cierto que una de las fuentes inspiradoras tiene su origen en la iniciativa de Uruguay fundada en la jurisdicción consultiva de Corte Internacional de Justicia y la Corte Interamericana de Derechos Humanos. Respecto de las opiniones consultivas en el ámbito de la Corte Internacional de Justicia, las mismas se encuentran reguladas en el Capítulo IV del Estatuto de la Corte. Estas pueden versar sobre cualquier cuestión jurídica, y la competencia consultiva puede ser solicitada por cualquier organismo autorizado para ello por la Carta de las Naciones Unidas, hoy en día, la Asamblea General y el Consejo de Seguridad. En cuanto a las Corte Interamericana de Derechos Humanos, el Pacto de San José de Costa Rica establece en su artículo 64 inciso 1, que los Estados y los órganos autorizados al respecto podrán consultar a la Corte sobre la interpretación de la Convención o de otros tratados relativos a la protección de los derechos humanos en los Estados americanos. Aquí la legitimación activa para la solicitud de opiniones consultivas resulta más amplia ya que incluye a los Estados partes de la Convención.

También hay que considerar que fue seguramente la acción o consulta prejudicial del derecho de la UE otra fuente que estuve presente al momento de redactar la norma. En este caso las sentencias del Tribunal de Justicia de la Unión Europea serán de aplicación obligatoria para los Tribunales Superiores de justicia del Estado consultante. Sin embargo, en el ámbito del Mercosur la solución no fue la misma y el art 11 del 
Reglamento del Protocolo de Olivos (RPO) expresamente dispone que las opiniones consultivas "no serán vinculantes ni obligatorias".

A este respecto es válido destacar el voto del Dr. Wilfrido Fernández de Brix, quien expresa que "con un sistema no obligatorio ni vinculante respecto al magistrado nacional, se desnaturaliza por completo el concepto, la naturaleza y el objetivo de lo que debe ser un correcto sistema de interpretación prejudicial"'. A su vez el Tribunal Permanente de Revisión del Mercosur (TPR) estableció que "Reiterando el criterio sentado en la OC $N^{\circ} 1 / 2008$, debe tenerse presente que las opiniones consultivas -tal y como se encuentran reguladas por las normas Mercosurno pueden ser asimiladas a los recursos prejudiciales por otros procesos de integración. En consecuencia, no corresponde al TPR indicar al juez la normativa que en definitiva habrá de aplicar. Tal facultad es de resorte exclusivo del propio juez, a quien le compete decidir esta materia en el marco del ordenamiento jurídico concreto, viabilizar el procedimiento y resolver no aplicar la norma interna al momento de resolver, si considera que viola la norma Mercosur invocada".

El art 2 RPO establece que todos los Estados partes del Mercosur actuando conjuntamente, los órganos con capacidad decisoria del Mercosur es decir: el Consejo del Mercado Común (CMC), el Grupo del Mercado Común (GMC) y la Comisión de Comercio del Mercado Común (CCM), junto con los Tribunales Superiores de los Estados partes con jurisdicción nacional en las condiciones que se establezcan para cada caso tienen legitimación para solicitar opiniones consultivas. Por primera vez se reconoce protagonismo a la justicia nacional contribuyendo al objetivo de este procedimiento que consiste en lograr uniformidad en la interpretación del derecho de la integración.

\section{TRIBUNALES SUPERIORES DE JUSTICIA DE LOS ESTADOS PARTE}

El art 4.1, RPO dispone que la consulta Deben referirse "exclusivamente a la interpretación jurídica" de la normativa del Mercosur siempre que se vinculen con causas que estén bajo tramite en el Poder Judicial del Estado parte solicitante". Por su parte el art 4.2, RPO establece que el procedimiento será reglamentado una vez consultados los Tribunales Superiores de Justicia de los Estados Partes. Consecuentemente, el CMC sancionó la Decisión $\mathrm{N}^{\circ} 2 / 07$ bajo el nombre "Reglamento del Procedimiento para la solicitud de Opiniones Consultivas al Tribunal Permanente de Revisión por los Tribunales Superiores de Justicia de los Estados Partes del Mercosur", cuyo art 1 declara que cada Tribunal Superior de Justicia de los Estados partes, actuando en

1 Opinión consultiva $N^{\circ}$ 01/2007, parágrafo III.2.B.4 (voto del Dr. Wilfrido Fernández de Brix).

$2 \mathrm{TPR}$, opinión consultiva $\mathrm{N}^{\circ} 01 / 2009$, párrafo 18 , 
sus respectivas jurisdicciones deberá establecer las normativa interna correspondiente para la solicitud de opiniones consultivas.

De acuerdo al artículo 4.2, RPO, deberá identificarse en cada país cuáles serán los tribunales superiores de jurisdicción nacional que presentarán las cuestiones ante el TPR. En consecuencia, la Decisión N²/07 (art. 2) dispone: "Considerase competentes para solicitar opiniones consultivas al TPR, los siguientes tribunales de los Estados partes: Por la Republica Argentina, Corte Suprema de Justicia de la Nación; por la Republica Federativa de Brasil, Supremo Tribunal Federal; por la Republica del Paraguay, Corte Suprema de Justicia; y por la Republica Oriental del Uruguay, Suprema Corte de Justicia y Tribunal de lo Contencioso Administrativo". Por su parte el mismo artículo de dicha decisión en su inciso 7 expresa que el TPR "solamente entenderá en la solicitud presentada" cuando: a) la solicitud proceda de unos de los Tribunales Superiores designados por los Estados parte; b) el pedido sea formulado de acuerdo con lo dispuesto en el art.4: c) la cuestión en causa no sea objeto de procedimiento de solución de controversias en curso sobre el mismo objeto.

\section{LA REGULACIÓN ARGENTINA}

La Corte Suprema de Justicia de la Nación (CSJN) mediante la Acordada $\mathrm{N}^{\circ} 13 / 08$ estableció las Reglas para el trámite interno previo a la remisión de las solicitudes de opiniones consultivas al Tribunal Permanente de Revisión del Mercosur. La misma dispone que:

Todos los jueces de la Republica, tanto de jurisdicción nacional como provincial, podrán formular en el marco de una causa en trámite ante sus respectivos estrados, a instancia de parte o de oficio, la solicitud de opiniones consultivas al Tribunal Permanente de Revisión del Mercosur de carácter "no vinculante ni obligatorio", sobre la interpretación jurídica de las normas del Tratado de Asunción, del Protocolo de Ouro Preto, de los protocolos y acuerdos celebrados en el marco de dicho Tratado, de las Decisiones del Consejo del Mercado Común, de las Resoluciones del Grupo Mercado Común y de las Directivas de la Comisión de Comercio " (art 1 de la citada acordada)

Deberán ser efectuadas por escrito y contener: a) la enunciación precisa de la caratula del expediente en el que se la formula; b) la mención del juzgado o tribunal ante quien tramita; c) la exposición del objeto de la solicitud; d) el relato claro y preciso de toda las circunstancias relevantes del caso que estén relacionadas con la solicitud; f) la indicación precisa de la normativa del Mercosur que constituye el objeto de la solicitud (art 2). Asimismo, podrán acompañarse las consideraciones relativas a la cuestión objeto de consulta que hubiesen formulado en el litigio las partes y el Ministerio Público, como también cualquier otra constancia 
que pueda resultar de utilidad a los fines de la emisión de la opinión consultiva (art 3).

Las solicitudes son elevadas a la CSJN por intermedio del superior tribunal de la causa. La Corte, previa verificación del cumplimiento de los recaudos exigidos, remite las solicitudes de opiniones consultivas al TPR, a través de su secretaria, enviando copia a la Secretaria del Mercosur y a los demás Tribunales Superiores de los Estados parte (art 5). Una vez recibida la comunicación de la admisión o del rechazo de una solicitud al TPR y de las opiniones consultivas emitidas por este órgano, la CSJN debe hacer saber lo dispuesto al juzgado o tribunal de origen por intermedio del superior tribunal de la causa que corresponda (art 6). Lo Corte debe llevar un registro de las solicitudes de opiniones consultivas dirigidas al TPR (art 7).

Estas reglas serán de aplicación en el ámbito de la CSJN cuando las solicitudes de opiniones consultivas al TPR sean directamente formuladas en causas en trámite ante su jurisdicción (art 8).

\section{CASO SANCOR 3}

Por primera vez, en el año 2009, la Corte Suprema de la Nación solicita una opinión consultiva al Tribunal Permanente de Revisión. Esta solicitud se enmarca dentro del caso "Sancor c. Dirección General de Aduanas de la República Argentina" en el cual se pone en discusión la aplicabilidad de los derechos de exportación establecidos por la resolución 11/2002 del Ministerio de Economía a diversas exportaciones de productos lácteos, de agua mineral, efectuadas por la actora en los años 2002 y 2003 a la República Federativa del Brasil y a la República del Paraguay.

La actora se opuso al pago de estos derechos, por considerar que son inaplicables respecto de exportaciones a países miembros del Mercosur, ya que serían contrarios a las disposiciones del Tratado de Asunción. La Cámara Nacional de Apelaciones en lo Contencioso Administrativo Federal, Sala V, revocó la sentencia del Tribunal Fiscal de la Nación y, en consecuencia, dejó sin efecto las resoluciones de la Aduana de Santa Fe impugnadas por la actora. Contra esta decisión el Fisco Nacional (Dirección General de Aduanas) interpuso recurso extraordinario, que fue concedido.

En este fallo el voto de la mayoría considero que se dieron todas las condiciones necesarias para que la solicitud de opinión consultiva tenga lugar. A) La Corte estableció en junio de 2008 las Reglas para el trámite interno previo a la remisión de las solicitudes de opiniones consultivas al Tribunal Permanente de Revisión del Mercosur; B) la cuestión se

3 CSJN, 06/10/09, "Sancor Cooperativas Unidas Limitada c/Administración Federal de Ingresos Públicos Dirección General de Adunas”. 
refiere exclusivamente a la interpretación jurídica de la normativa del Mercosur (art 4 punto 1 de la Decisión del CMC 37/03); C) la consulta se encuentra vinculada a una causa que está bajo trámite del Poder Judicial de la Republica Argentina.

La única disidencia corresponde a la Dra. Highton de Nolasco quien sostuvo que la solicitud de opinión consultiva no era procedente porque resulta extemporánea, al no haber sido introducida al contestar el recurso extraordinario (en virtud de la decisión adoptada por la Corte en la causa G.1207.XLIII). Siguiendo el análisis realizado por la Dra Eloísa B. Raya de $\mathrm{Vera}^{4}$ en relación al mismo fallo, podemos observar cómo, esta decisión se contrapone con el texto de la Acordada 13/2008, en la cual no existe ningún plazo ni momento procesal para la interposición de la solicitud de opinión consultiva. Por otro lado hay que tener en cuenta que tanto las normas primarias como el derecho derivado del Mercosur tienen primacía sobre la ley interna argentina de acuerdo a lo establecido en el artículo 75 inciso 24 de nuestra Constitución Nacional que dispone que las normas dictadas en consecuencia de los tratados de integración tienen jerarquía superior a las leyes. Por su parte el artículo 75 inc. 22 dispone la supremacía de los Tratados y concordatos en relación al derecho interno.

A su vez, la Dra. Highton esgrime un argumento relativo al contenido y a la legitimación activa para negar la solicitud. En relación al contenido, establece que "tratándose del reclamo de un particular -persona jurídica nacional del Estado contra el cual aquel se dirige-, relativo a los "derechos de exportación" de bienes de ese mismo origen, no media en el caso elemento alguno que autorice al primero a requerir una opinión consultiva pues no se encuentran en juego, de modo directo, eventuales derechos de algún otro u otros Estados Partes del Mercosur, ni tampoco de algún nacional de aquellos".

Contrariamente a la lógica expresada por la magistrada, en este caso, estamos frente a una relación regional, ya que nos encontramos con un particular nacional de un Estado parte (Argentina), cuya mercadería pretende exportar a Brasil y Paraguay, dos Estados miembros del Bloque regional. Por lo tanto es necesario aplicar la legislación Mercosureña ya que se trata sin dudas de una relación regional que involucra una actividad comercial entre tres miembros del Mercosur.

En relación a la falta de legitimación activa, la magistrada considera que "fuera del procedimiento correspondiente a los Tribunales Superiores de Justicia... a ninguna de las partes involucradas en la presente contienda le ha sido reconocida legitimación para solicitar individualmente y de modo directo una opinión consultiva al Tribunal Permanente de Revisión”.

4 Eloísa B. Raya de Vera, Comentario sobre el fallo de la Corte argentina sobre la opinión consultiva en el Mercosur, Espacio de Opinión, http://www.diputadosmercosur.gov.ar/ espaciodeopinion/?gac_id=40. 
Por el contrario, la Acordada 13/2008 de la Corte Suprema de Justicia de la Nación, en su artículo 1 dispone: "Todos los jueces de la República, tanto de jurisdicción nacional como provincial, podrán formular en el marco de una causa en trámite ante sus respectivos estrados, a instancia de parte o de oficio, la solicitud de opiniones consultivas...". Por lo tanto el particular puede solicitar una opinión consultiva, si se cumplen los siguientes requisitos: a) que esté en juego la interpretación de normativa Mercosur y b) que se vincule a alguna causa en trámite ante el Poder Judicial, luego corresponderá a la Corte Suprema decidir si la eleva o no al Tribunal Permanente de Revisión. Por lo tanto la legitimación activa de la actora, se encuentra supeditada, en última instancia, a la decisión de la Corte respecto del caso en cuestión.

\section{CONCLUSIÓN}

Luego de haber realizado un breve análisis de la regulación que hace el Derecho del Mercosur y la Republica Argentina acerca del procedimiento de solicitud de opiniones consultivas al Tribunal Permanente de Revisión, es importante dejar en claro que este mecanismo está lejos de considerarse perfecto y por lo tanto definitivo, que por el contrario, debe estar sujeto a futuras modificaciones, que permitan al Mercosur desarrollar un derecho propio, vinculante para los Estados parte y que tienda a el continuo progreso de la normativa mercosureña.

La no obligatoriedad de la interpretación normativa dada por el Tribunal, juntamente con la falta de práctica, tanto por parte delos Estados miembros, órganos decisorios del Mercosur y Tribunales Superiores de los Estados parte, contribuyen a que el sistema consultivo se mantenga inerte. Es necesario un compromiso fuerte, de todo el conjunto de actores que componen el Sistema de Integración del Mercosur, para que esta herramienta, ya vislumbrada en el Protocolo de Olivos encuentre su efectiva aplicación, y permita desarrollar un conjunto de normas, cuya interpretación dada por el Tribunal Permanente de Revisión resulte obligatoria y determine el futuro de esta institución. Es precisamente este último quien posee una herramienta eficaz cuyo uso puede determinar el sentido correcto de las normas del Mercosur, tanto primarias como derivadas de los órganos decisorios.

El alcance que se le asigne al contenido de estas normas, contribuirá sin duda al desarrollo del derecho de la integración en el marco del Mercosur, sin embargo los Estados parte deben esforzarse por cumplir con la interpretación dada por el Tribunal y trabajar conjuntamente para que sus órganos de justicia recepten el derecho mercosureño y comprehendan la importancia de la adecuación del derecho interno a esta ultima normativa. Solo así nos aproximaremos a la conquista de un derecho de tipo supranacional, el cual nos ha servido de fuente de 
inspiración a la hora de diseñar el actual sistema que nos rige.

\section{REFERENCIAS BIBLIOGRÁFICAS}

AMERASINGHE F. Chittharanjan (2010) Jurisdiction of International Tribunals, La Haya: Kluwer Law International.

CALOGERO Pizzolo (2008) Sistema de Solución de Controversias, Mercosur. Buenos Aires: EDIAR.

CALOGERO Pizzolo (2010) Derecho e Integración Regional: Comunidad Andina, Mercosur, SICA, Unión Europea. Buenos Aires: EDIAR.

CZAR DE SALDUEÑO Susana (2007) La primera opinión consultiva en el Mercosur. Buenos Aires, en La ley - suplemento de derecho constitucional.

RUIZ DIAZ LABRANO Roberto (2006) Las opiniones consultivas ante el Tribunal Permanente de Revisión del Mercosur a través de los Tribunales superiores de los Estados partes, en Anuario de Derecho Constitucional Latinoamericano. Fundación Konrad-Adenauer-Stiftung, tomo I.

Tratado de Asunción, 1991.

\section{Legislaciones Consultadas}

Carta de las Naciones Unidas, San Francisco, 26 de junio 1945

Convención americana sobre derechos humanos (Pacto de San José), San José, Costa Rica, 22 de Noviembre 1969.

Opinión consultiva $N^{\circ}$ 01/2007: planteada por la Sra. Jueza de Primera Instancia en lo Civil y Comercial de Primer Turno de la jurisdicción Asunción, Paraguay, vía la Corte Suprema de Justicia de la República del Paraguay, Asunción (Paraguay), 3 de abril de 2007.

Opinión consultiva $N^{\circ}$ 01/2008: solicitud cursada por la Suprema Corte de Justicia de la República Oriental del Uruguay con relación a los autos del Juzgado Letrado de Primera Instancia en lo Civil de $1^{\circ}$ turno IUE 2-32247/07 "Sucesión Carlos Schenk y otros c/Ministerio de Economía y Finanzas y otros. Cobro de pesos", Asunción (Paraguay), 24 de abril de 2009.

Opinión consultiva $N^{\circ}$ 01/2009: presentada por el "Juzgado Letrado de Primera Instancia en lo Civil de $2^{\circ}$ Turno - Autos: Frigorífico Centenario S.A. c/ Ministerio de Economía y Finanzas y otros. Cobro de pesos. IUE: 2-43923/2007. Exhorto. "República Oriental del Uruguay. Asunción (Paraguay), 15 de junio de 2009.

Protocolo de Olivos, 2002.

Protocolo de Ouro Preto, 1998 